\title{
IN THE BEGINNING WAS THE 'DIMENSIONS'. THEN, EVENING PASSED AND MORNING CAME - THE 'SOCK' IN DOCTORAL RESEARCH
}

\author{
Asha Sara Mammen ${ }^{* 1}$ 瓜 \\ ${ }^{* 1}$ Research Scholar, CHRIST (Deemed to be University), Bengaluru, India
}

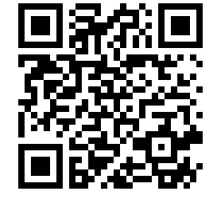

DOI: https://doi.org/10.29121/granthaalayah.v8.i6.2020.350

Article Type: Research Article

Article Citation: Asha Sara

Mammen. (2020). IN THE

BEGINNING WAS THE

'DIMENSIONS'. THEN, EVENING

PASSED AND MORNING CAME -

THE 'SOCK' IN DOCTORAL

RESEARCH. International Journal of Research -GRANTHAALAYAH, 8(6), $133-141$.

https://doi.org/10.29121/granthaa

layah.v8.i6.2020.350

Received Date: 01 May 2020

Accepted Date: 25 June 2020

\section{Keywords:}

$\mathrm{PhD}$

Doctoral Research

Significant

Originality

Contribution

Knowledge

\section{ABSTRACT}

An evaluation and understanding of that genre of academic degree attributed as the highest academic recognition bestowed by a university the $\mathrm{PhD}$ or the doctoral research programme, is the aim of this essay article. The attributes or nature of the doctoral programme are referred to by the writer as 'dimensions'. The researcher utilized various reliable sources both offline and online and gathered information from seminars and talks of intellectuals from the academia in synthesizing information to create a piece of writing that comes from the prespective of an early research scholar. Research projects are done by way of a dissertation at all levels of higher education. The question asked is - can we carry the same mindset, structure and rigour of the research undertaken at the undergraduate level of education, or more precisely, the master's research to the $\mathrm{PhD}$ research programme? And of course, can there be that confidence that one can bring or feel or have as a result, to the PhD programme? Furthermore, a question that is asked in the doctoral education programme is - whether a scholar creates or invents knowledge? Or is it the use of the philosophical frameworks of the science of knowledge, in attempting to bring out what is already there, to be justified and tested, thus classifying and giving it an orderly and labelled existence, which then becomes the new form of knowledge? Doctoral research projects undertaken are of various orientations, yet there is that element, a movement to the 'SOCK' which makes a PhD worthy. This research paper reviews and shares insights from the perspective of an early research scholar on the various premises and claims to make rationale the arguments/research questions stated.

\section{INTRODUCTION}

A doctoral programme is that genre of study requiring a unique way of thinking - critical, divergent, convergent, creative using all the faculties of mind - pure reasoning, practical reasoning and aesthetics; classified on a hierarchy as the highest degree granted by a University.

At all levels of higher education, research projects are done by way of a dissertation. The question is - can we carry the same mindset, structure and rigor of the research undertaken at the undergraduate level of education, or more precisely, the master's research to the $\mathrm{PhD}$ research programme? And of course, can that confidence that one brings or feels or have; as a result, help while studying the PhD programme?

(C) 2020 The Author(s). This is an open access article distributed under the terms of the Creative Commons Attribution License, which permits unrestricted use, distribution, and reproduction in any medium, provided the original author and source are credited. 
In the Beginning Was The 'Dimensions'. Then, Evening Passed and Morning Came - The 'Sock' In Doctoral Research

Brabazon (2018) is quoted as saying 'It is knowledge that makes philosophy 'philosophy'. The Doctor of Philosophy education is a journey that starts with knowledge and could never culminate in knowledge as knowledge grows, very true and in line with the famous quote of Issac Newton "If I have seen further it is by standing on the shoulders of giants". Thus, leading to a set of research questions that is asked in the doctoral education programme - whether a scholar creates or invents knowledge? Or is it the use of the philosophical frameworks of the science of knowledge, in attempting to bring out what is already there, to be justified and tested, thus classifying and giving it an orderly and labelled existence, which then becomes the new form of knowledge.

This research paper explores and reviews the various premises and claims to make rationale the argument stated in terms of the 'dimensions' of a doctoral programme leading to the understanding of a major element 'SOCK' that distinguishes a doctoral research project.

\section{THE DOCTORAL STUDY - PhD}

A doctoral programme is a study and a training where a candidate works towards achieving a degree that is refered to as PhD (Philosophiae Doctor or Doctor of Philosophy)/Doctorate. The candidate who has completed the initial period of study called a course work and then working on a dissertation is called a research scholar or doctoral student or PhD student. PhDs are awarded across academic disciplines. Doctoral students form a key component of knowledge production which is documented in a doctoral thesis (Baptista et al., 2015). The thesis is a hardcopy following a template as set by the respective university and it embodies years of study culminating in an intellectual output. The output of a doctoral study as put forth by the Quality Assurance Agency for UK Higher Education states it is 'an output that constitutes original research as defined by the academic community into which the candidate wishes to be admitted' (QAA,2011, p.12). There is an academic community called examiners that validate and rate the quality of the thesis based on set criterias, which the term 'SOCK' is associated with. The 'dimensions' as specified in the title, elaborates on the definition of a PhD programme and is detailed below.

\section{DIMENSIONS OF A DOCTORAL PROGRAMME}

As one takes upon this doctoral educational journey, there are some preliminary understanding required of the research scholar regarding the structure of the course. Most of the failures that occur in teaching and learning are attributed on the regulation, assumptions or learning process or outcomes, syllabus, teaching padagogy, pattern of instruction, expectations not being shared between the student and teacher (Brabazon, 2018). How a research scholar operates depends on the nature and type of the doctoral programme. The knowledge or expectation / assumptions of a PhD programme can be understood in the following aspects:

- Regulation - The regulations and structure of the doctoral programme depends on the model adopted. $\mathrm{PhD}$ regulations mention of a minimum time duration given towards the completion, requirement - to do or not to do a course work which is a form of a foundation course that prepares a scholar to develop the right mindset, supervisor-supervisee relations and to learn the methodologies in the conduction of research. Requirements regarding refereed indexed publications and paper presentations in conferences, types of examination and assessments, contractual agreements governing the conduct of the candidature.

- Mode of evaluation - Where there is a coursework, it has to be completed successfully by means of gaining the required classroom or online attendance and completing of a series of assignments; training the candidate in the various aspects of research work. The coursework designed when sincerely engaged with and further analyzed while doing the related assignments will provide an impetus while entering into the research endeavor of the doctoral programme. As mentioned by Greenspoon (2013), definitely the coursework compliments the research and provides a good knowledge base and foundation, for a time when one completely engages in the research work. A scholar may or may not get the chance to understand the foundations later, but once learnt during the sessions of the course work, it will reignite when the mind goes with the flow of the research activities. Sometimes the research is carried in parallel or started after the period of course work. The quality of the dissertation is accessed finally by examiners of experience and caliber, national or international, initially internal examiners and then on to 
examiners external to the university. The progress of the research work in various stages is evaluated by a board of members forming a research advisory committee or doctoral committee and finally approval by an external examiner on the finalization of the research proposal, signaling to proceed to engage in the active study. Ultimately the thesis is approved and accepted by public defense in the presence of external examiners.

- PhD is nationally distinctive - There are models of the doctoral programme that are unique to a particular group of countries. Australia, New Zealand, United Kingdom follows a particular model. North America, Canada and USA follows its own distinctive model, South East Asia and African nation have developed their own model of the PhD Programme. One can find a British model implemented in a university in an African nation. Specific and interesting models are developed, further improvised and then implemented across Universities across boundaries (Brabazon, 2018).

\section{METHODOLOGY AND METHOD}

This research paper is structured in the form of an academic essay or review paper. The researcher utilized various reliable sources both offline and online and gathered information from seminars and talks of intellectuals from the academia in synthesizing information to create a piece of writing that comes from the prespective of an early research scholar. Prominent information was gathered from the academic vlog of Dr. Tara Babazon, Dean of Graduate Research at Flinders University, Adelaide, Australia. Reseach papers related to the theme has also been used to consolidate on the knowledge related to the topic under study. The qualitative method adopted was an unstructured interview with PhD students over different years of registration on their personal and academic experiences they go through in the PhD study.

\subsection{QUALITATIVE ANALYSIS ON EXPERIENCES OF RESEARCH SCHOLARS}

Interviews and discussions with research scholars over different years of registration/candidature gave mixed responses regarding different aspects of the doctoral programme. The researcher was able to determine and understand that the type of journey and the experience a research scholar undergoes; vary as time progresses within the PhD candidature.

Initially, during the orientation programme, there are expectations, full of dreams and a huge motivation to conquer the unimaginable in terms of identification of research problem, research gaps and extensive reading, following which the reality of experiences start. In the course work period, there is a different experience, writing of assignments to meet deadlines and group works taken in classroom sessions/webinar sessions, enable more insight into one's own persona and abilities, moreover understanding that in this intellectual journey, every research scholar has a valuable attribute and cannot be ranked on a scale from one to ten as per performance or intellect. The period that follows after is when, the investigator believes where scholars implement the lessons learnt during the coursework period. Here is where, for the writer, the stories of Socrates, Descartes come to mind, also of Issac Newton, Robert Hook, Leibniz in terms of explaining to the team of faculty and doctoral committee members, how through the scientific methods of reviewing existing literature, that small niche area was found, using variables to study the gap and its relevance in solving that research problem or argument. Scholars mention of the conflicts and tensions related to the pressure of conveying the originality in knowledge contribution and in addition, of the moral support and encouragement from other stakeholders - of the value of friendship and family ties, of the faith in divinity that gives them the stamina and courage to move forward.

\section{DISCUSSION OF THE FIRST SET OF ARGUMENTS}

The first set of research questions - Can we carry the same mindset, structure and rigour of the research undertaken at the undergraduate level of education, or more precisely, the master's research to the PhD research programme? And of course, can there be that confidence that one can bring or feel or have as a result, to the PhD programme?

The answer lies in understanding the processes that takes place in a Masters level of dissertation and a PhD level dissertation. In the former, the research is synthesizing knowledge where as in the latter it is original 
In the Beginning Was The 'Dimensions'. Then, Evening Passed and Morning Came - The 'Sock' In Doctoral Research

knowledge (Brabazon, 2018). In comparing synthesising with originality, synthesis is consolidating results from different sources or studies and interpreting them in the context of an existing evidence (observation that needs scientific understanding). Synthesis of knowledge comes from the process called reviewing of existing literature or research studies already published. This leads also to indentification of a research gap or knowledge gap that can be considered for future studies. Knowledege synthesis has its importance and is crtical in advancing practice, research and policy (Whittemore, 2014). The importance of originalitiy is a criteria that cannot fail in a PhD research work. Orginality has a higher standing and requires greater effort with intectellual and emotional investment. It includes the process involved in knowledge synthesis plus more. Knowledge synthesis is the starting of knowledge translation. Knowlegde translation are those activities that enable research efforts and implications to move from research institutes into the hands of people and organisations that can put it into pratical use. This is also where the research article takes the effort to dissiminate the understanding of 'SOCK' in doctoral research.

Thus, to answer the reason question put forth: the mindset, structure and rigour that one needs as one enters into the world of doctoral research is of a higher notch. Taking from the words of Mike Murdock, motivational speaker and writer from the book 'The Leadership Secrets of Jesus', the writer mentions that 'Jesus's mission on earth was His life'. The writer also mentions that 'Jesus was very busy'. Busy by teaching, traveling, preaching, performing miracles and mentoring to get His mission accomplished. From the realm of Christian theology, this can be the essence of the research in doctoral studies too. Scientific research studies undertaken by Linnenbrink-Garcia et al. (2012) and Cordova et al. (2014) found that confidence in prior knowledge coupled with learner characteristics (meta-cognitive judgement, self-efficacy, interest, scientific understanding and misconceptions) and conceptual change-based interventions facilitated learning new information. Learners with high confidence in prior knowledge along with self-efficacy and interest promoted conceptual change information learning. Mason et al. (2008) research study on academic learning proved how the role of topic interest, text (knowledge) and epistemological beliefs explained conceptual change learning or learning new conflicting information. In the context of the current study, learner characteristic of the $\mathrm{PhD}$ aspirant or $\mathrm{PhD}$ students coupled with interest in the topic, and epistemology processes possibly could facilitate getting into the rigour, mindset and structure of a doctoral study.

The above research studies and interpretation in relation with the current study validates the argument that a $\mathrm{PhD}$ aspirant can bring or feel or have that confidence as a result of a sincerely undertaken Master's level research work to the PhD research programme.

\section{SOCK - SO WHAT IT REALLY IS?}

The author understands that the thesis or the doctoral project report is validated by examiners on whether it is an original research and not a duplicate or plagiarized work. An original work that extends the boundary of knowledge and thats why the term 'contribution to knowledge'is used.

There is now this movement that is much prominent, from the term 'original' to 'significant original' with regard to 'contribution to knowledge' in doctoral studies. Some seasoned academician and researchers consider it, an interesting and stimulating movement, some disagree but to the writer it is in line with the thrill of a treasure hunt, navigating and searching the sands and oceans of intellect to find that special intellectual diamond mine, wanting to be polished to purity and preciousness - this is the essence of the term 'significant original contribution to knowledge'-SOCK.

\section{THE INTERPRETATION OF SOCK}

SOCK expands and flows from significant original contribution to knowledge but for interpreting purpose, the writer proposed to follow in an order of, a much-understood term to the lesser explored term, following the path starting with knowledge, contribution, originality and then significance.

\section{Knowledge}

Knowledge is a cruicial element in scholarly life. Over the years, based on how knowledge accumulates and grows, its definitions also gets modified. Definitions are derived based on the context or circumstances; knowledge is applied. A pratical and everyday explanation considers it to be a theoretical or practical understanding of a subject 
or topic gained through formal or informal means. It purports to suggest that one understands an entity whether it be facts, ideas, or series of concept. The earliest philosopher, Plato defines knowledge as 'justified true belief'. Knowledge cannot be just belief, emotion, feeling or assumption one holds. Belief alone in something does not make it true. Those belief, assumptions or even emotions and feeling that are justified, verified, tested, understood, evaluated, experimented and proved is considered as knowledge.

\section{DISCUSSION OF THE SECOND SET OF RESEARCH QUESTIONS}

The second set of research questions that are asked in this research article is whether a scholar creates/invents knowledge in doctoral education? Or is it the use of the philosophical frameworks of the science of knowledge, in attempting to bring out what is already there, to be justified and tested, thus classifying and giving it an orderly and labelled existence, which then becomes the new form of knowledge?

The platonian theory puts verified true belief as knowledge meaning it already exists in the crude form as beliefs but unreliable for scientific verifications and applications. That which is evaluated by scientific methods becomes justifiable and true and used in various forms. Knowledge of different forms has its own audience and it needs to be disseminated for implications and purposes that benefit micro, meso and macro levels (Brabazon, 2018). Thus, in a doctoral programme, a scholar converts beliefs into knowledge, converts knowledge from one form into another, disseminates it thereby not creating or inventing it; which answers the first part of the research question.

The approach to answering the second part of research question lies in the fact there is an abundance of knowledge in this world. Knowledge can be re-proved with new or even older methods, giving it a new interpretation, further adding to the body of knowledge. Thus, the definition put forth by Davenport and Prusak (1998) states that 'knowledge is a fluid mix of framed experiences, values, contextual information, and expert insights that provides a framework for evaluating and incorporating new experiences and information.' The 'framework' links with the concept of paradigms. To approach the vast body of knowledge, we have paradigms, followed by theories.

Paradigms enables study or research to be done within a standard organized worldview. In doctoral education, the researcher identified his area of study or problem of study and places it in the paradigm. A paradigm is a standard way of looking at something quite contrary to the personal everyday way of thinking (Decarlo, n.d.). It makes observing, understanding, investigating a research problem standing within a specific worldview (Kuhn, 1962). Each paradigm has its own classification of knowledge of what is real or already known - ontology, what can be know epistemology and how we can know it - methodology/methods. It is through the methods/methodology adopted that we take the epistemological knowledge and put it into the ontological knowledge, thereby contributing a new addition to the body of knowledge.

In the research world, there is another aspect of knowledge, we call as theory. Rubin \& Babbie (2017) defines theory as 'a systematic set of interrelated statements intended to explain specific phenomena.' Paradigm is broader in prespective while theory has specificity in its prespective. Paradigms point us in a particular direction when the 'why' questions are asked about an observation or pattern or an activity happening and theories give the explanation of the 'how' behind the 'why' (Decarlo, n.d.).

\section{Contribution}

In literally context, the term 'to contribute' denotes the role a person or object plays in the development or progressions of any entity. In the doctoral education context, it refers to what is done leading to 'advancement of knowledge', thus the continuous phrase 'contribution to knowledge'. Another aspect, that speaks out when considering contribution, is the term 'importance'. To contribute, that element of a new way of thinking (new interpretation), to the attribure under study is to render it 'important'. 'Contribution to knowledeg' asks the question of how the student has intervened in their field or subject ot discipline (Brabazon, 2018). The questions then enquired is; how is contribution to knowledge realised in a research project. Brabazon (2018) answers that question by stating that contribution can be a contextualization of a theory or dataset, expanding an already existing model, combining one or two ideas and creating something new - working in line with the idea of multidisciplinarity, interdiciplinarity and transdisciplinarity. When one thinks in the line of the word 'impact', it scaffolds towards working on the research project that faciliates thinking divergently resulting in an addition. 
In the Beginning Was The 'Dimensions'. Then, Evening Passed and Morning Came - The 'Sock' In Doctoral Research

\section{Originality}

The defining characteristics a $\mathrm{PhD}$ research endeavor is that it must demonstrate, confirm and verify originality rather than just claim it. It is an intellectual manifesto for a researcher and his work. Focussed precision of understanding originality enables the researcher to pinpoint with clarity the original contribution to knowledge. The question arises now, how is this originality in a research endeavor measured or demonstrated or confirmed. It is demonstrated when a strong and expansive grasp of the literature related to the topic under investigation is analysed and studied and verified by literature review or systematic review. The purpose of doing such a review demonstrates that the researcher has an understanding of the current state of knowledge.i.e., knowing where the knowledge in at; right now and termed as the original state of knowledge which facilitates to show that the researcher is competent to make an originality towards knowledge contribution. Further through research methods that are transparently presented, the researcher applies it to the current state of knowledge such that it is moved somewhere else or to something new. Thereby, stating that the original knowledge system by means of research methods is moved to originality satisfying being demonstrated, confirmed, verified, being transparent and meaningful (Brabazon, 2018).

\section{Originality - either in process or in the outcome}

Research papers by Guetzkov, Lamont \& Mallard (2004); Lamont (2009); Lovitts (2007) in Baptista et al. (2015), puts forward an interesting and motivation aspect of putting in and making a revelation of originality in a doctoral research. Originality comes not just from the outcome but also from the overall process that produces an outcome. It is more than being novel or unique and can be manifested through the structure of the PhD work.

The research paper titled 'Making supervision work for you'(Wellington, 2010) brings out a viewpoint of originality in doctoral studies by stating that originality is 'evident through the research design, the way the knowledge is synthesized, formulating the implications and even the way in which the research is presented'. Bennich-Björkman (1997) and Beghetto (2013) agree that originality can be defined as something that is new or novel, but does not necessarily have to be applicable or relevant. Here is where Baptista et al. (2015) points out the relationship of originality with creativity and innovation stating that each attribute can stand individually as well as works collectively in a doctoral research.

Originality can be in the form of generating a new original technique or observation or result. It can be where one can have an original idea or develop an original method or new algorithm. Original testing of another idea used with required permissions - moving that test or model to a new location, empirical work that has not been done before, applying an old technique to a new area, applying or finding new evidence that throws light on an old issue (Brabazon, 2018).

\section{Originality - Discipline specific}

Different disciplines has their own way of demonstrating and confirming originalty (Baptista et al., 2015). In science, technology, engineering and mathematice discipilines, originality is defined by publishability while in arts, humanities and social sciences, it is related to intellectual originality (Clarke and Lunt, 2014). Another comparison with regard to originality comes from the study of Guetzkow et al. (2004) where the researchers argue that in the discipline of natural sciences, originality is defined as the production of new findings and new theories whereas in social sciences and humanities, it involves using a new approach, theory, method, or data; studying a new topic, doing research in an understudied area; or producing new finding. Baptista et al. (2015) identifies that students are influenced in their perception and expectations on ways of doing $\mathrm{PhD}$, also in the viewpoints on it as a process and product based on their disciplines.

\section{Significance}

The most important and the new word that is making a debute in the world of research is the term 'Significant' in the SOCK terminology. The other four words - original, contribution, knowledge (OCK) are known to a broader range of researchers and it is accounted to be verifiable in the research process.

The term'significant' as per Oxford English dictionary is as follows - meaningful and purposeful, that which makes a difference - notable, an absolution to the why and how - reason and understanding, impact and influence, noticeable effect or change, bringing a new outlook to an old aspect, compelling, remarkable.

There is a difference from the term 'statistical significant' which is commonly used as a research vocabulary, mostly in the statistical analysis chapters. 
Discussions and talks on the term 'significance' brings out, firstly, the concern students have on how it is measured or verified, mostly by examiners, as the unofficial viewpoint that exists is 'significance is in the eye of the beholder'. Based on the above argument, there needs to be an unambuiguity for scholarly community on how to approach this term, when it is used as an important criteria in evaluating the quality of a doctoral thesis.

This research paper has utilized the elaborate detailing given by the Dr Tara Babazon, Dean of Graduate Research at Flinders University, Adelaide, Australia to provide clarification and direction to scholars and members of the academia regarding the need mentioned above.

Dr Brabazon (2018) has enumerated four strategy used internationally to help students to grasp and prove the significane of their research endeavour. The four points are:

- Explaining why the research was worth doing? By explaning the importance of the research questions. Brabazon (2018) advises students to start with the research question and show why it is important in terms of worth.

- Why the findings actually matter? Convincing the significane of the findings arrived at.

- Explain how the research transforms theory?

- Explain the generalisabilty or lack of generalisability from the research.

Brabazon (2018), further breaksdown the word 'significance' to make it more measurable by asking the following questions.

- Does your research have value?

- Was the contribution worth-making?

- Does it capture interest of stakeholders? Is the research making economic, social or cultural contribution? Is it significant in this direction?

- has link with the term 'impact'. Is it working with the policy or political flavor of the day?

- Does it meet the scope and scale required for a doctoral study in terms of reading required or the dataset?

- Significance is not about the size, a small discovery can have a major impact or have big importance.

'The above criterias are in line with the expectation of students mostly, to be aware of how to work, think or progress structuring their research'quote Brabazon (2018)

There is a prespective too that exists as mentioned by Brabazon (2018), where the vlogger quotes that in the examination space, significane comes as a gift and inclined to subjectivity of the examiner, it comes from their personal prespective. Some research topics can be viewed as important, some as significant, some other with originality of novel thoughts and ideology only.

\section{Originality and Significance: The nuanced variation}

The research paper by Lovitts (2005) mentions two distictions that brings out the essence of originality versus significance. The distinction are what brings about an incremental shift in knowledge and a substancial shift in knowledge. Lovitts (2005) points out that the former is achieved by applying existing methods to new data while the latter is achieved by application of new methods, new questions or new ideas. Baptista et al. (2015) identifies that it is this variability that underscores the emphasis on significance in a doctoral research. Even though Johnston (1997) states that significance is not inherently a component of originality, Tinker \& Jackson (2004), notes that original research in the context of doctoral education is expected to provide knowledge of significance to the field of study.

\section{CONCLUSION}

In the context of a doctoral study, the words spoken by a fascinating thinker and philosopher, Joseph Joupert resonates, 'the aim of argument, or of discussion, should not be victory, but progress'. Process for all the stakeholders associated with the doctoral education primarily the PhD student. An understanding and evaluation of the scope and attributes required in the doctoral education is attempted here whereby ensuring the early research scholars to proceed and process the knowledge with the SOCK in mind. There is an element of risk associated with doctoral education coming in through the requirement of producing original knowledge. MacKinnon (1970) agrees that 
In the Beginning Was The 'Dimensions'. Then, Evening Passed and Morning Came - The 'Sock' In Doctoral Research

courage and confidence to take risk in choosing a topic and methodoly, to think divergently and critically and put forth a way of thinking or new approach to understand a phenomena is an essential characteristics of a humble and focused PhD student. In any ways, the best thesis, as mentioned by authoritarians in the field, is a completed thesis with all the chapters in place with the details of the work academically written as telling a story. A best doctoral study is a study that has completed its run to graduation.

\section{SOURCES OF FUNDING}

None.

\section{CONFLICT OF INTEREST}

None.

\section{ACKNOWLEDGMENT}

None.

\section{REFERENCES}

[1] Brabazon, Tara.]. (2018, June 2). Vlog115 - [SOCK (Significant original contribution to knowledge!)].

[2] Baptista, A., Frick, L., Holley, K., Remmik, M., \& Tesch, J. (2015). The Doctorate as an Original Contribution to Knowledge: Considering Relationships between Originality, Creativity, and Innovation. Frontline Learning Research, 3(3), 55-67.

[3] Bennich-Björkman, L. (1997). Organising Innovative Research: The Inner Life of University Departments. Oxford: IAU Press, Pergamon.

[4] Clarke, G., \& Lunt, I. (2014). The concept of 'originality' in the Ph.D.: how is it interpreted by examiners? Assessment \& Evaluation in Higher Education, 39(7), 803-820.

[5] Cordova, J. R., Sinatra, G. M., Jones, S. H., Taasoobshirazi, G., \& Lombardi, D. (2014). Confidence in prior knowledge, self-efficacy, interest and prior knowledge: Influences on conceptual change. Contemporary Educational Psychology, 39(2), 164-174.

[6] Cray, H. (2014, August 6). How to make an original contribution to knowledge. Retrieved from University AffairsAffaires Universitaires: http://matt.might.net/articles/successful-phd-students

[7] Decarlo, M. (n.d.). Paradigms, theories, and how they shape a resewarcher's approach. Retrieved from Scientific Inquiry in Social Work. Retrieved https://scientificinquiryinsocialwork.pressbooks.com/chapter/6-2-paradigms-theories-and-how-theyshape-a-researchers-approach/

[8] Frick, B. L. (2018). The original contribution: Myth or reality in doctoral work. Spaces, journeys and new horizons for postgraduate supervision, 12, 275.

[9] Greenspoon, A. (2013, April 3). Nine things you should consider before embarking on a PhD. Retrieved from Elseiver.

[10] Guetzkov, J., Lamont, M., \& Mallard, G. (2004). What is Originality and the Humanities and the Social Sciences? American Sociological Review, 69(2), 190-212.

[11] Johnston, S. (1997). Examining the examiners: An analysis of examiners' reports on doctoral theses. Studies in Higher Education, 22(3), 333-347.

[12] Kuhn, T. (1962). The structure of scientific revolutions. Chicago, IL: University of Chicago Press.

[13] Linnenbrink-Garcia, L., Pugh, K. J., Koskey, K. L., \& Stewart, V. C. (2012). Developing conceptual understanding of natural selection: The role of interest, efficacy, and basic prior knowledge. The Journal of Experimental Education, 80(1), 45-68.

[14] Lovitts, B.E. (2005). Being a good course-taker is not enough: A theoretical perspective on the transition to independent research. Studies in Higher Education, 30(2), 137-154. 
[15] MacKinnon, D. (1970). Creativity: A multi-faceted phenomenon. In J.D. Roslansky (Ed.), Creativity (pp. 17- 32). Amsterdam: North-Holland.

[16] Mason, L., Gava, M., \& Boldrin, A. (2008). On warm conceptual change: The interplay of text, epistemological beliefs, and topic interest. Journal of Educational Psychology, 100(2), 291-309.

[17] Odendaal, A., \& Frick, L. (2018). Research dissemination and PhD thesis format at a South African university: The impact of policy on practice. Innovations in Education and Teaching International, 55(5), 594-601.

[18] Rubin, A., and Babbie, E. R. (2017). Research methods for social work (9th ed.). Belmont: Wadsworth.

[19] Tinkler, P., \& Jackson, C. (2004). The Doctoral Examination Process. Maidenhead: Open University Press.

[20] Wellington, J. (2010). Making supervision work for you. London: Sage

[21] Whittemore, R., Chao, A., Jang, M., Minges, K. E., \& Park, C. (2014). Methods for knowledge synthesis: an overview. Heart \& Lung, 43(5), 453-461. 